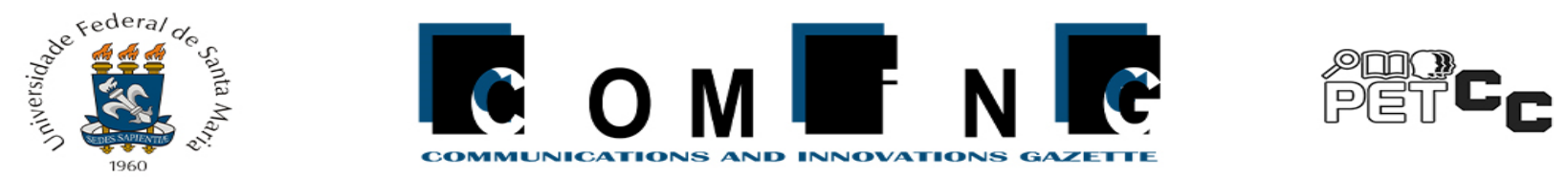

\title{
Podcast Vozes do 40A: da ideia à execução
}

\author{
Chrystian Revelles Gatti ${ }^{1}$, Érika Mariana Marques Gonzales ${ }^{1}$, Gabriel Isais dos \\ Santos Aires ${ }^{1}$, Robson Severo ${ }^{1}$, Victoria Heloina Almeron Lopes dos Santos ${ }^{1}$, Taís \\ da Silva Martins ${ }^{2}$
}

${ }^{1}$ Programa de Educação Tutorial (PET) do curso de Letras, Centro de Artes e Letras Universidade Federal de Santa Maria

${ }^{2}$ Departamento de Letras Clássicas e Linguísticas - Universidade Federal de Santa Maria

\footnotetext{
chrystian.revelles@acad.ufsm.br, erikammgonzales@gmail.com, gabsneidom@gmail.com, robsonsevero39@gmail.com, tais.martins@ufsm.br, victoria. lopeseacad.ufsm.br
}

Abstract. The objective of this article is to present Vozes do $40 \mathrm{~A}$ Podcast, an Extension-program Project developed by academics enrolled in the Tutorial Education Program (Programa de Educação Tutorial) at Federal University of Santa Maria (UFSM) for the purpose of approximating Faculty of Letters' teaching staff members with the graduate students and also those who are interested. Beyond exposing podcast production step-by-step, we approach relevant subjects of the development of the project through reflections to create a scientific identity encompassing research. Among other things, we highlighted how important this Extension Project is as a vehicle for dissemination of the voices which have been sharing knowledge daily on the 40A Building.

Resumo. Esse artigo tem como objetivo apresentar o podcast Vozes do 40A, um projeto de extensão promovido pelos integrantes do Programa de Educação Tutorial do curso de Letras (PET Letras) da Universidade Federal de Santa Maria (UFSM), criado com o propósito de aproximar os professores das Letras aos estudantes dos/nos cursos da UFSM e demais interessados. Além da exposição passo-a-passo da confecção do podcast, abordamos assuntos pertinentes ao desenvolvimento do projeto como reflexões para a criação de uma identidade científica que abarque as pesquisas das Letras. Assim, destacamos a importância do podcast enquanto veículo que divulga as vozes de quem compartilha saberes diariamente no $40 \mathrm{~A}$.

\section{Apresentação}

O podcast Vozes do 40A é um projeto de extensão ${ }^{1}$ do Programa de Educação Tutorial do curso de Letras (PET Letras) da Universidade Federal de Santa Maria, no qual buscamos interagir informalmente com os professores dos cursos de Letras da UFSM (bacharelado em português e licenciaturas em português, inglês e espanhol). As pautas de conversa vão desde as produções acadêmicas do professor aos seus gostos fora de sala de 
aula e, diríamos, até fora do arco da Universidade ${ }^{2}$ - histórias pessoais e de como ingressaram no Curso de Letras. Os episódios são postados mensalmente nas plataformas Spotify, Youtube e Anchor ${ }^{3}$.

É importante destacar que até meados de março de 2020, o Vozes do 40A sequer estava no planejamento do PET Letras. O começo desse projeto de extensão aconteceu por conta dessa abrupta interferência mundial - a pandemia. Justamente pela suspensão de atividades presenciais e do distanciamento social decretado, os projetos planejados para as atividades de 2020 do PET Letras tiveram de ser reinventados. Entre várias ideias, levantamos a possibilidade de ser criado um ambiente em que os professores dos Cursos de Letras ${ }^{4}$ da UFSM pudessem falar sobre a sua trajetória acadêmica, assim, surgindo o podcast.

O podcast Vozes do 40A ainda não passava de um esboço até que, durante o mês de março, esquematizamos as etapas necessárias para efetivar o programa. Em abril, a temática estava concebida: saber mais sobre a formação e os interesses dos professores, até porque isso sempre interessou aos estudantes dos cursos. Porém, distantes fisicamente - longe das salas de aula, dos corredores e do ambiente acadêmico -, ficou muito mais difícil o contato entre professor e aluno em relação a questões extra-sala de aula. Por isso, acreditamos que o Vozes do 40A possa, minimamente aproximar professores e alunos, pois são integrantes do PET Letras que elaboram as perguntas e os roteiros, conversando diretamente com o docente e usando uma linguagem informal.

Com suas etapas já planejadas, era preciso dar uma identidade ao projeto. Então, foi adotado o nome "Vozes do 40A" - analogia com o prédio do 40A -, tão simbólico para os estudantes de Letras já que, somente após mais de 50 anos de Curso, em 2017, eles conquistaram um lugar para chamar de seu. Por muitos anos, os discentes de Letras peregrinaram entre os prédios da UFSM e, finalmente, no dia 31 de outubro de 2017, foi inaugurado o prédio 40A Letras, um lugar onde os sujeitos das/nas Letras podem, além de assistir aulas, circular e compartilhar histórias. Abaixo, o prédio 40A, lugar onde vivemos boa parte de nossas experiências universitárias. Não apenas nós estudantes, como também os professores que nos contam suas histórias, suas preferências e sobre seus objetos específicos de estudo, transitam por ali:

2 Monumento localizado na entrada do campus sede da Universidade Federal de Santa Maria.

3 Link para os nossos canais de streaming:

Spotify: https://open.spotify.com/show/5Rkga14z3a6TJQswfKRwtq

Youtube: https://www.youtube.com/channel/UCHPb2W57VtL3PruTVVWhTXg

Anchor: https://anchor.fm/vozes-do-40a

4 Os cursos de Letras da Universidade Federal de Santa Maria são: Bacharelado em Letras - Português/Literaturas; Letras - Licenciatura - Habilitação: Português e Literaturas de Língua Portuguesa; Letras - Licenciatura - Habilitação: Espanhol e Literaturas de Língua Espanhola; Letras - Licenciatura - Habilitação: Inglês e Literaturas de Língua Inglesa. 


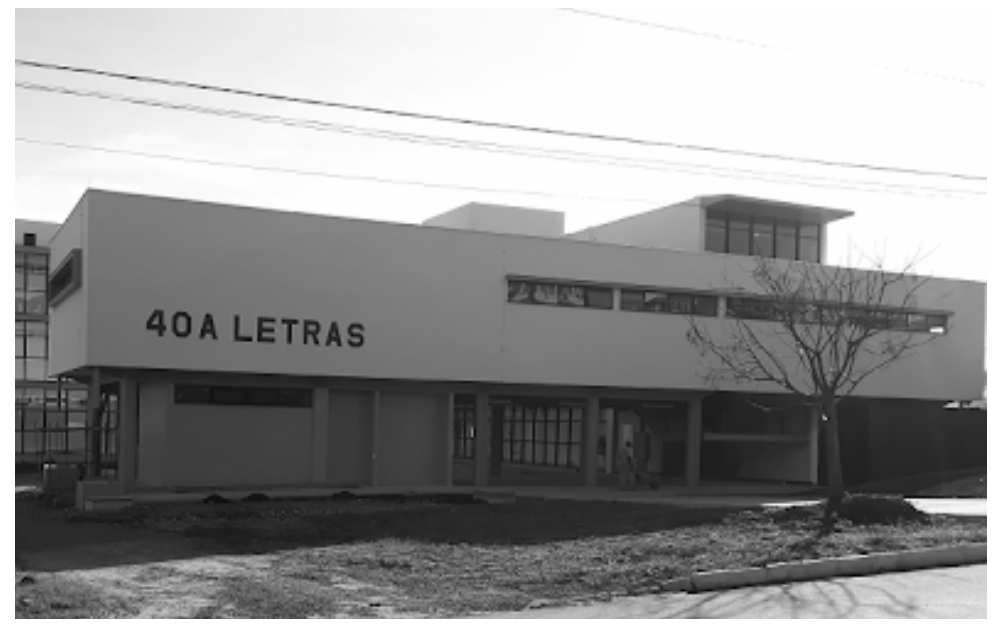

Figura 1: fachada do prédio $40 A^{5}$

A fim de consolidarmos nossa marca - afinal todo podcast tem uma -, era necessário criar uma identidade visual. Pensando em toda a carga simbólica e identitária que o prédio do curso de Letras traz consigo, foi criada a imagem que oficializamos como logotipo do projeto. Abaixo, seu design como aparece em cada um dos episódios lançados:

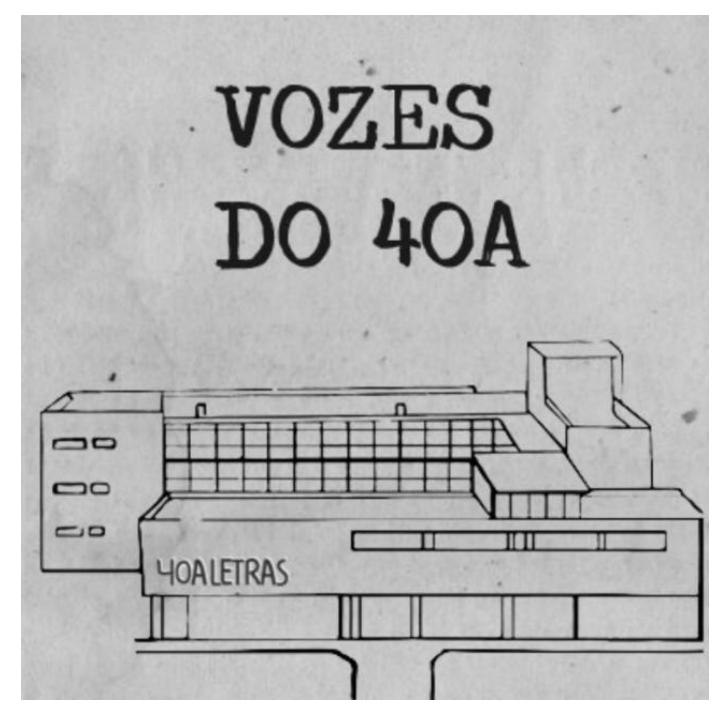

Figura 2: arte do logotipo criado por Victoria dos Santos

5 Imagem retirada do site http://demartini.com.br em 19 de outubro de 2020. 


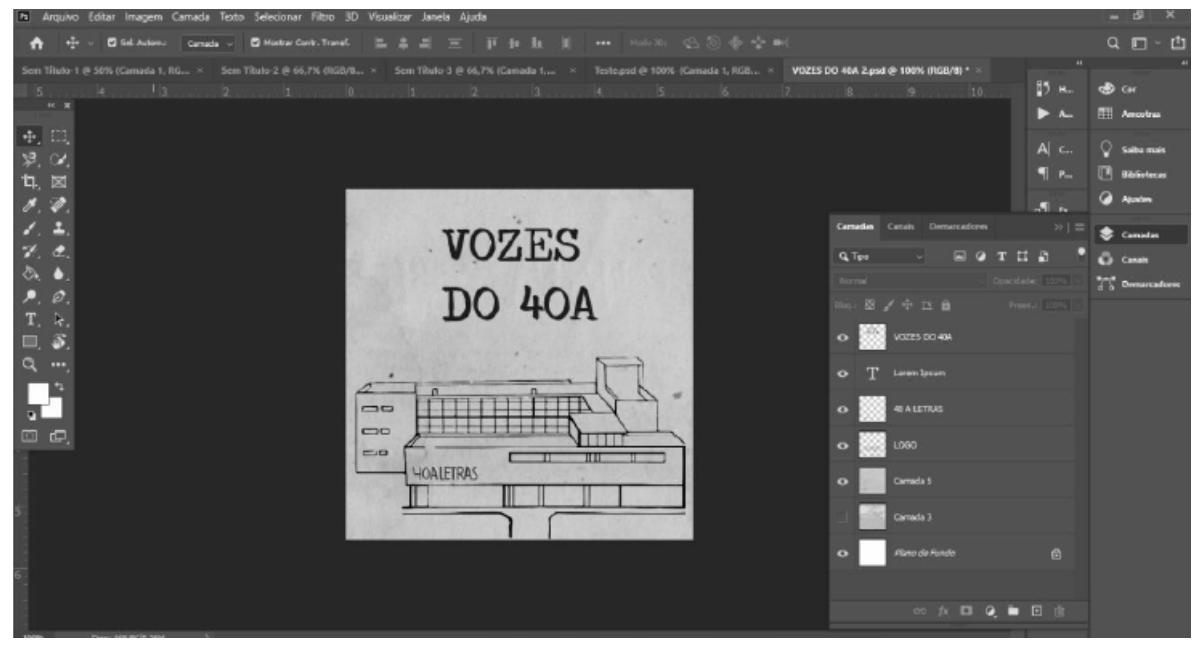

Figura 3: processo de criação da arte no Adobe Photoshop CS6

\section{Reflexões sobre o papel do podcast na Universidade}

Entender a escolha desse formato (o de podcast) demanda uma visita ao seu surgimento, quando, de acordo com Eduardo Vicente (2018, p.3), podcast significava apenas a disponibilidade para download da gravação de um programa de rádio feito ao vivo. Sua etimologia é autodescritiva, pois a palavra podcast tem sua origem na junção de $i P o d$, um dispositivo de reprodução de áudio, com broadcast, que traduzido do inglês significa transmissão de rádio. Seguindo a história da palavra, essa etimologia traz o que inicialmente poderia ser um podcast: uma ferramenta para manutenção de programas de rádio a fim de serem reproduzidas, quantas vezes fosse desejado, no iPod. No entanto, desde seu surgimento em 2004, o podcast foi conquistando novos lugares e transformando-se em relação às emissoras, emancipando-se.

Justamente por não ser ao vivo, no decorrer dos anos surgiram diversas temáticas de podcast como diários, talkshows, debates, fofocas, ou até mesmo perpassando práticas atualmente difundidas, como meditação, auto-ajuda $A S M R$, etc. Com tantas opções, o formato de podcast seria uma excelente opção. Como a ideia era produzir episódios em série, o programa de podcast encaixou perfeitamente com a proposta, principalmente por podermos utilizar das diversas plataformas de vídeo chamada, sem nos restringirmos a nenhuma, necessitando somente da criatividade e de alguns programas de edição.

Não seria possível dar tanta qualidade à empreitada sem o auxílio dos programas utilizados na identidade visual e na edição. Nosso podcast não é completamente autônomo, pois utiliza softwares pagos ao longo de todo o processo de produção. No entanto, o recurso do Ministério da Educação e Cultura (MEC) não permite a compra desses softwares indispensáveis. Para possibilitar o uso desses programas de empresas privadas tivemos que recorrer a outras fontes de recursos da instituição. Ressaltamos essa questão porque, apesar de atuarmos dentro de uma instituição pública, necessitamos, para os processos de gravação, de edição, de publicação e de divulgação, de ferramentas de empresas privadas, pois mesmo que haja programas gratuitos, não são tão intuitivos e práticos quanto os que habitualmente utilizamos.

Enfim, todos esses fatores colaboraram para que o Vozes tenha dado certo em um formato híbrido - nem totalmente formal, nem totalmente informal, uma vez que os próprios assuntos acabam sendo, acima de tudo, divulgação científica. Nosso podcast 
alcança, parafraseando Eduardo Vicente (2018, p. 11), relevância social, cultural e política, já que destaca e divulga as vozes que produzem ciências nas áreas de linguística e na literatura.

\section{Construção de um podcast como projeto de pesquisa, ensino e extensão}

Parte do que diferencia o podcast de uma gravação comum de áudio é a qualidade da produção. Da mesma maneira que apreciamos um filme, uma textura, um alimento ou uma fragrância pela sensação de prazer que ela instiga quando experienciada, um podcast deve ser igualmente instigante e estimulante para quem escuta. Para que o áudio tenha plena qualidade, não basta apenas abrir o microfone e falar - é preciso conhecimento de programação e de operação de áudio, de interesses do público e de divulgação visual. Assim, visualizamos o podcast não como material produzido em massa, mas como algo a ser confeccionado individualmente, uma vez que a história de cada professor é única. No esquema abaixo, nos propomos a explicar rapidamente os comandos a priori que todos os episódios devem ter:

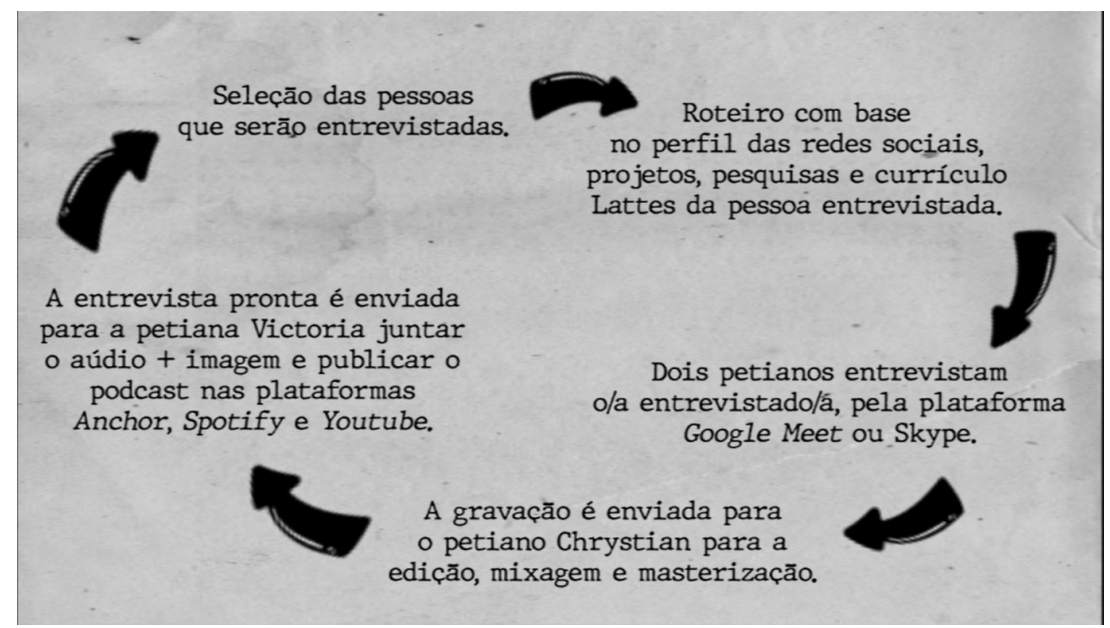

Figura 4: quadro explicativo sobre a produção dos episódios do podcast

No entanto, além desses comandos iniciais, o método de produção é rigoroso e exige uma sincronia do grupo do podcast, que conta com a participação de cinco petianos, junto com a tutora do PET Letras, professora Taís Martins. Entre os integrantes, Érika e Robson como roteiristas e entrevistadores, Chrystian como editor de áudio, Victoria como editora visual e Gabriel como revisor geral. É com essa divisão de tarefas, que conseguimos organizar o projeto de extensão de forma que ninguém se sobrecarregue. Nos propomos, então, a explicar detalhadamente o método utilizado, a fim de compartilhar possibilidades que funcionam.

Primeiramente, é marcada uma reunião do grupo para decidir qual professor será entrevistado. O critério de escolha demanda a alternância entre departamentos do curso. Após a seleção do professor-convidado do mês, a tutora realiza o primeiro contato com o professor, convidando-o para participar do podcast, como no recorte da carta-convite a seguir: 

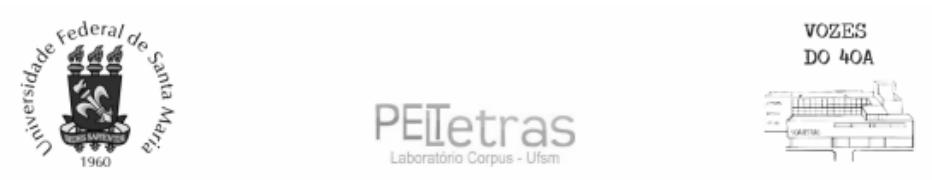

\section{PET LETRAS CONVIDA}

Caro Professor

O PET Letras tem o prazer de convidá-lo para participar de uma conversa para a gravação do podcast Vozes do 40A. Essa é uma atividade que objetiva integrar alunos e professores dos cursos de Bacharelado e de Licenciatura em Letras, por meio de uma conversa informal, que versará não só sobre a produção acadêmica dos entrevistados, mas também sobre seus interesses extra-sala de aula.

\section{Figura 5: recorte da carta-convite enviada a um dos professores do curso de Letras}

Após o convite, contatamos o docente por e-mail ou pelo aplicativo WhatsApp para sanar as dúvidas técnicas do professor em relação à entrevista. É marcada a melhor data para todos, professor e entrevistadores. Com o convite já aceito e a data da entrevista marcada, planejamos um roteiro de acordo com uma pesquisa feita especialmente para cada professor-convidado, com base no currículo lattes e outras redes sociais, script-base sobre o que poderia ser explorado nesse espaço de tempo, tendo em vista uma duração máxima de 60 minutos. Os entrevistadores começam apresentando o convidado. Logo após, inicia-se a conversa com a seguinte pergunta - "como você decidiu que queria cursar Letras?":

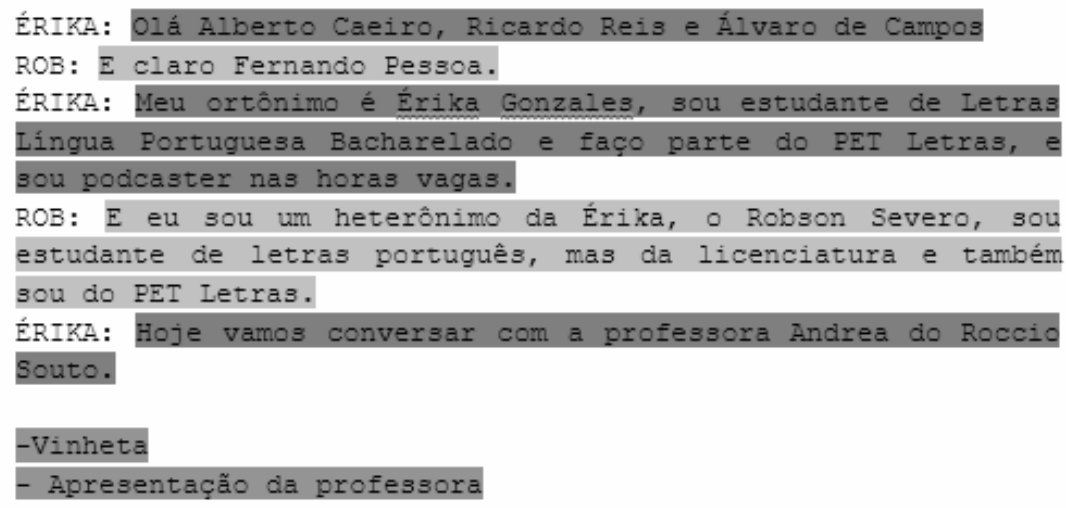

Figura 6: imagem de um roteiro esqueleto 
No dia da conversa, os entrevistadores chamam o professor-convidado alguns minutos antes da hora marcada para confirmar se está tudo funcionando e enviar o link do Google Meet. Já na chamada, antes de começar a gravação, o convidado é instruído a deixar, também, um celular perto com o gravador de voz ativado, para conseguir uma faixa de áudio individual e nítida. A obtenção de um arquivo de som separado para a voz de cada participante é essencial no processo posterior da edição de som, em que serão atenuados detalhes particulares aos gravadores, aos ambientes e até mesmo ao timbre de voz de cada um deles.

Com a gravação feita, o convidado é instruído a mandar a gravação do celular para o e-mail do PET Letras, para o WhatsApp ou para o Google Drive, de modo que os entrevistadores reúnam todas as gravações de áudio - a gravação coletiva, gerada pela própria plataforma do Google Meet -, e as gravações individuais dos celulares, reunindoas numa única pasta (para a entrevista em questão) do Google Drive.

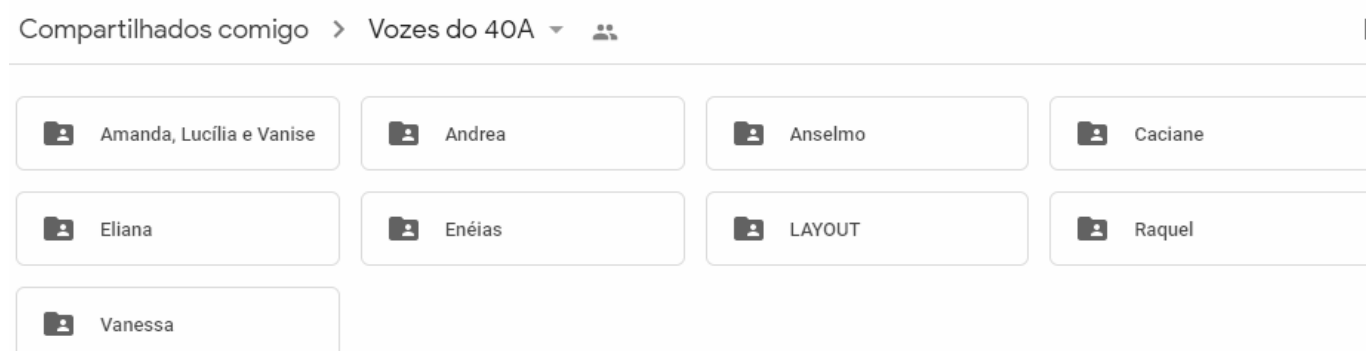

Figura 7: pasta no drive do podcast

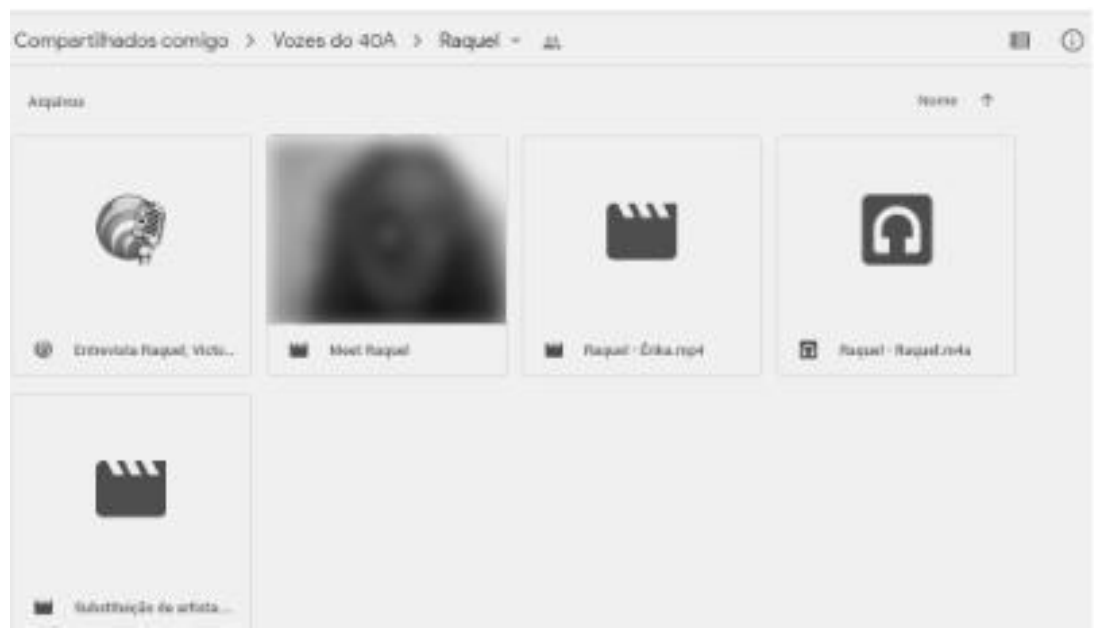

Figura 8: pasta específica de uma professora-convidada

O processo de edição de áudio passa por três fases, respectivamente denominadas: inicialmente, compressão e normalização; em seguida, sincronização, cortes, equalização e reverberação; finalmente, a masterização. Na primeira delas, os arquivos baixados são importados para um programa simples e gratuito - o Audacity. Nele, ainda em formato de celular, passam pelo processo de Compressão e Normalização: no primeiro, têm seus volumes altos abaixados e os menores aumentados para tornar a escuta mais uniforme, sem grandes variações (que ocorrem, por exemplo, quando a pessoa se afasta ou se aproxima do microfone, ou quando fala baixo demais); no segundo, são cortados os picos de volume, estabelecendo uma referência uniforme entre 0 e 1 decibéis. 


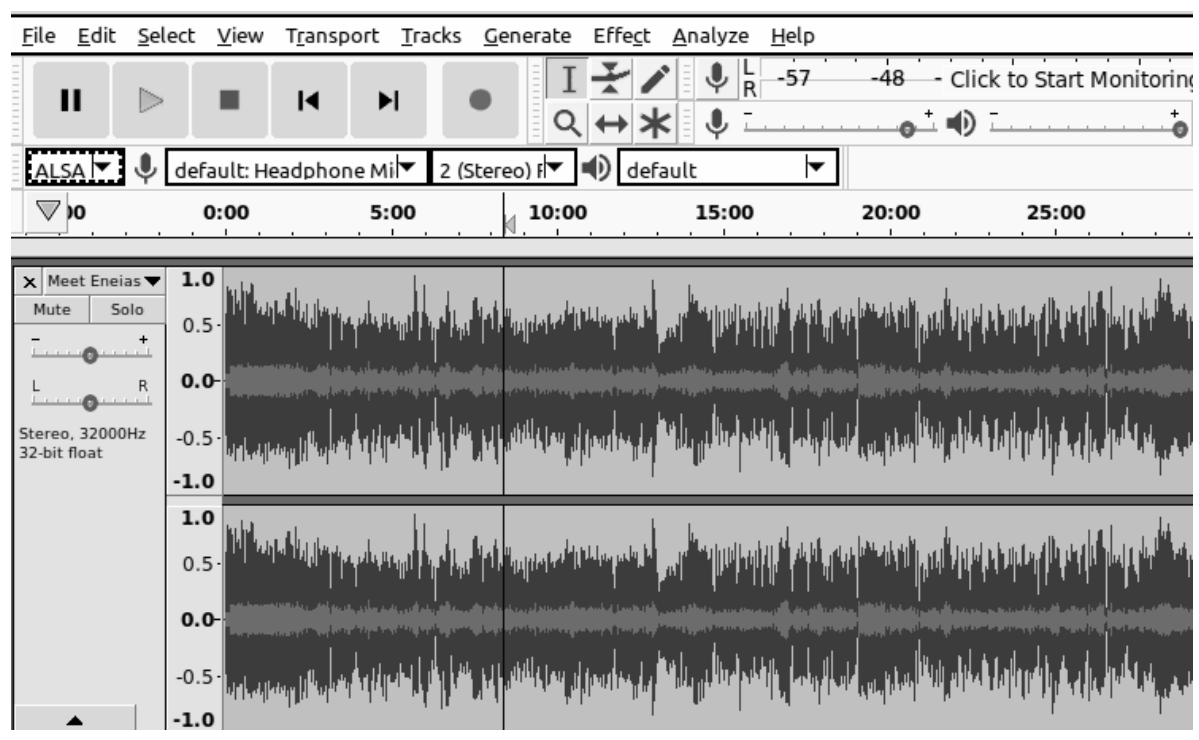

Figura 9: programa AUDACITY onde o áudio é importado

Após essa primeira parte, os arquivos são exportados no formato "WAV" de alta qualidade. Na segunda fase, são importados para o software privado REAPER, onde são sincronizados no tempo. Dá-se início à edição propriamente dita, cortando tudo o que for possível - ruídos, repetições, trechos que saíram do assunto ou que o próprio professor tenha solicitado corte, etc. A intenção dessa fase é reduzir o máximo da duração de toda a gravação. Para isso, até mesmo os silêncios entre as falas são cortados, tornando a conversa o mais dinâmica possível.

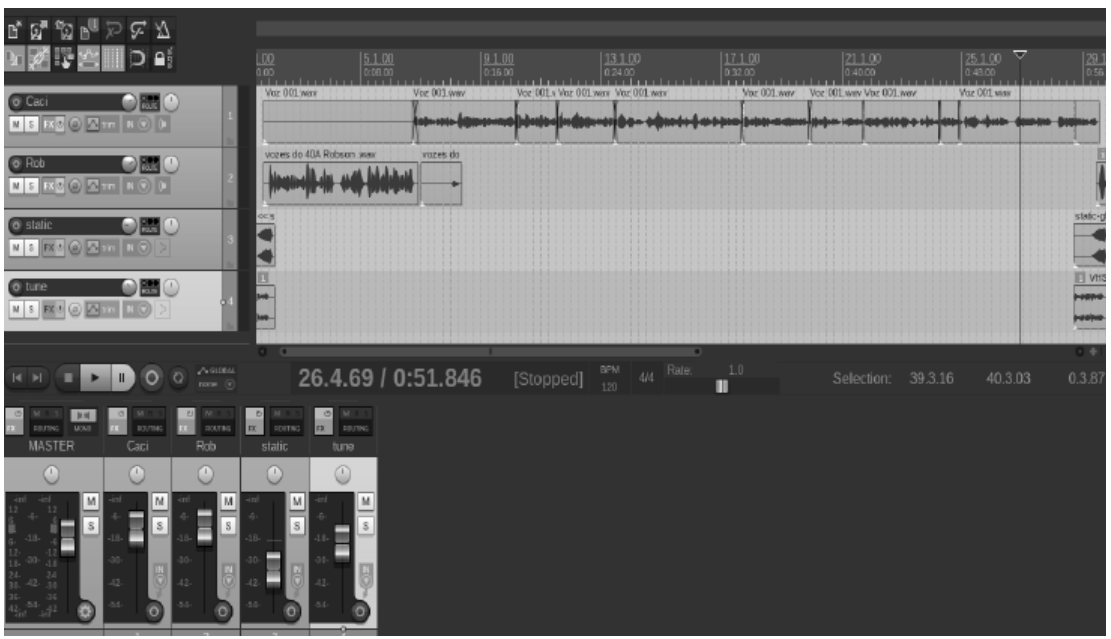

Figura 10: software REAPER usado na edição de áudio

Feito isso, cada faixa segue para o processo de Equalização. Nele, são revisadas as frequências do espectro da onda de cada voz, de modo a compensar os graves onde há pouco, atenuar o agudo onde há muito para "reequilibrar" o som, neutralizando peculiaridades do gravador usado. Depois disso, um pouco de reverb é adicionado a cada gravação - é uma pequena reverberação que dá a impressão de se estar numa sala, aplicada sob medida na faixa de cada um (dependendo da própria reverberação natural do ambiente em que gravaram). Então, uma segunda Compressão é realizada, desta vez atenuando a variação entre as faixas (enquanto a primeira neutralizou os picos e os baixos dentro de uma só, essa equilibra as faixas entre si, dando uniformidade ao volume da conversa como um todo). 


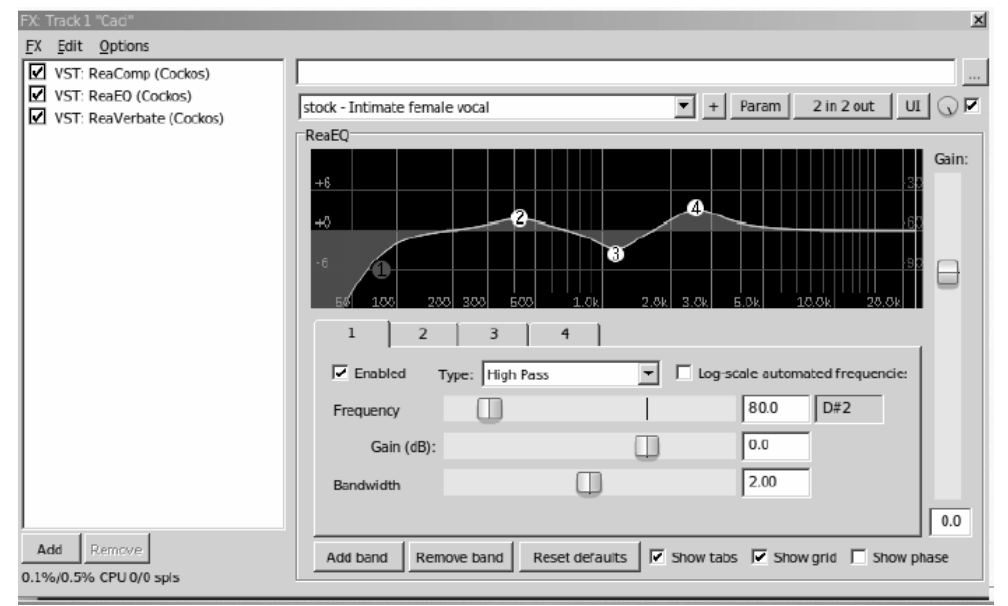

Figura 11: equalização no software REAPER

Parte-se para a última fase da produção do som, a masterização, na qual é gerada uma faixa final stereo que sintetiza as individuais e as renderiza para um arquivo final ".WAV" de alta qualidade, que é enviado para a edição visual.

Depois da edição do áudio, é postado um trecho de um minuto da entrevista, divulgando-a uma semana antes nas redes sociais. No Adobe After Effects, é inserida uma animação mostrando o spectrum do áudio seguindo o tempo de gravação e a entonação das vozes. Por fim, ainda no Adobe After Effects, é importado o arquivo ".WAV" gerado na masterização do som e associado à imagem-identidade do Vozes do 40A. Já a divulgação, no entanto, é postada apenas nas redes sociais do PET Letras. A seguir, uma das divulgações compartilhadas no Instagram do PET Letras:

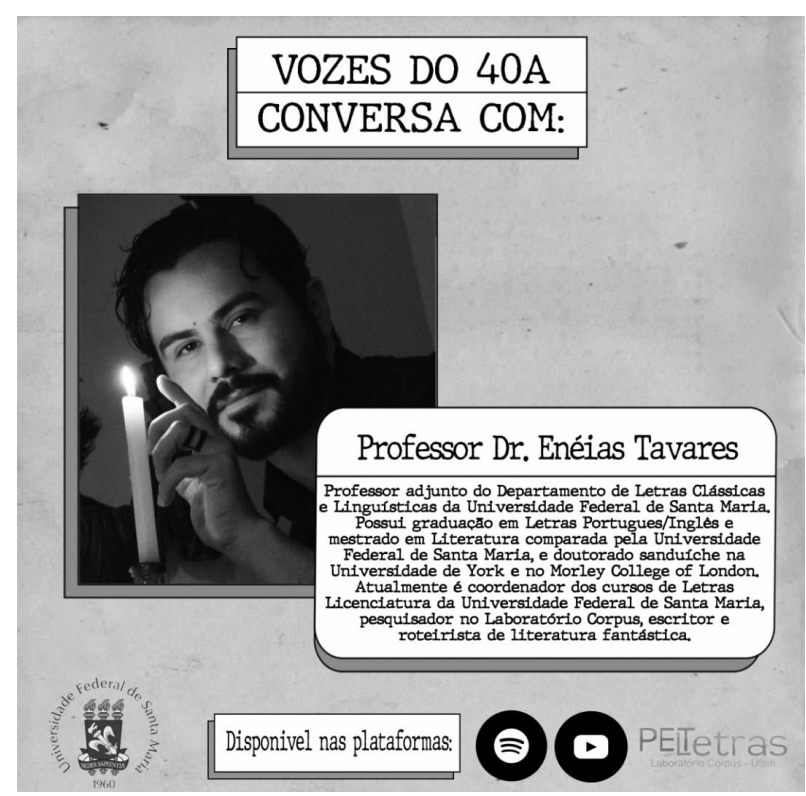

Figura 12: divulgação do episódio N.10: Conversa com o Prof. Dr. Enéias Tavares

Dá-se então a edição visual do episódio completo, ou seja, a montagem com a foto do professor, junto ao logo da UFSM e do PET com uma breve descrição. Com a imagem, uma breve descrição divulga o link para o podcast completo e o seu respectivo número do episódio, sendo a partir daí postado o arquivo final, cujo upload é feito na plataforma Anchor, que através de um feed RSS, permite a publicação do programa em 
diversas plataformas de streaming nas quais nosso podcast pode ser escutado, como Spotify, Deezer, Apple Podcast, entre outros. Além disso, uma imagem com o logo do Vozes do 40A é anexada ao áudio no programa Vegas Pro, e logo após, divulgada em nossa página do YouTube: PET Letras UFSM ${ }^{6}$.

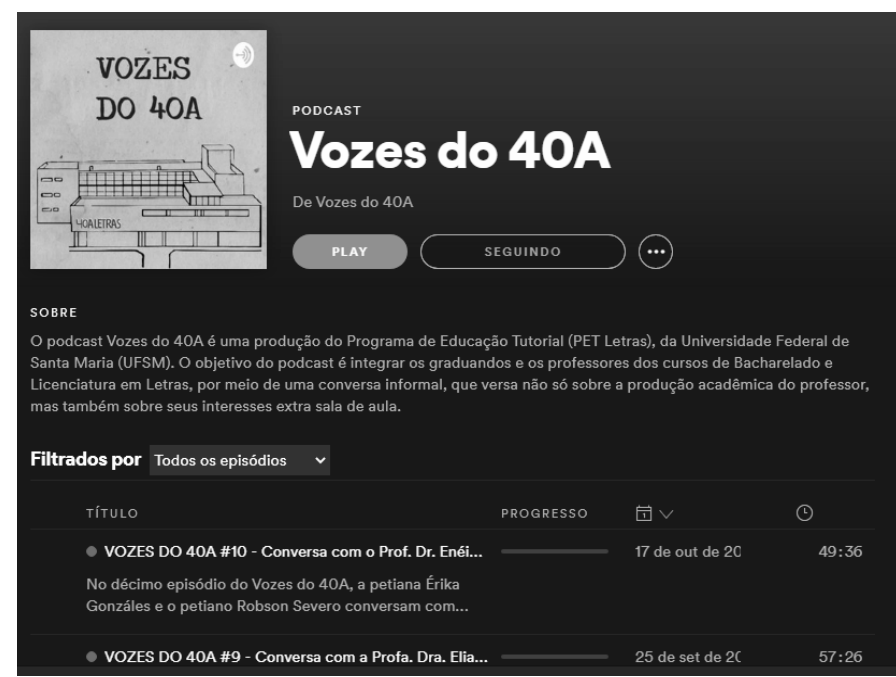

Figura 13: canal do Vozes do 40A no Spotify

Sem qualquer uma dessas etapas, o podcast não pode ir às plataformas. Por conta disso, reforçamos a exigência de pontualidade e de organização sincrônica. Ou seja, a primazia da comunicação, do coletivo e da organização necessárias para realização deste projeto de extensão. Um resultado satisfatório espelha boas relações e interações, só possíveis onde há respeito, dinâmica e humanidade.

\section{Reflexões e resultados}

Já que o podcast surgiu com o intuito de aproximar, em tempos de pandemia, os professores e os alunos dos cursos de Letras da UFSM, entendemos que a conversa deveria ser informal e descontraída. As perguntas feitas são uma retrospectiva na história profissional e, muito naturalmente, também pessoal, do docente, trazendo memórias de sua formação acadêmica e dos seus percalços em eventos, viagens, amizades e outras experiências que os protocolos universitários nos proporcionam.

De modo geral, os professores acabam compartilhando relatos marcantes e conselhos que podem ajudar os discentes em sua própria vivência enquanto acadêmicos de Letras. Uma certa pergunta sempre gera muito impacto, servindo não somente para os graduandos em formação, como também para quem deseja cursar Letras: "poderia deixar um conselho ou uma dica para quem estuda ou quer estudar Letras?". É sempre respondida de forma inusitada - vai além do evidente "deve gostar de ler" — os professores respondem com reflexões profundas sobre a língua, a linguagem, a comunicação, o discurso, o gosto pelo conhecimento de maneira geral, pois no curso de Letras se estuda arte, filosofia, história, geografia, anatomia e tudo quanto se fizer necessário para entender esse objeto de estudo tão amplo que é a linguagem humana. 


\section{Demais informações sobre o projeto}

O projeto "Vozes do 40A - circulação e divulgação do conhecimento" (054341) ${ }^{7}$, está disponível nas plataformas do Youtube e do Spotify. Atualmente articulados para a publicação de um episódio por mês, é importante estar atento às nossas redes sociais que são, no Facebook, PET Letras - Laboratório Corpus ${ }^{8}$, e no Instagram, @ petletraslabcorpus ${ }^{9}$, as plataformas nas quais divulgamos nosso conteúdo.

Mesmo para os que se encontrem em outras áreas fora das Letras, não deixamos de recomendar o Vozes, pois, além das ótimas histórias e recomendações de livros excelentes, os professores trazem reflexões e comentários necessariamente pontuais sobre produção de ciência, o mundo acadêmico e a importância da Universidade pública e de qualidade para todos.

\section{Referências bibliográficas}

MARTINS, Taís. Vozes do 40A. Vídeo publicado no Farol UFSM, Santa Maria, Rio Grande do Sul, Agosto 2020. Disponível em: https://farol.ufsm.br/video/taismartins?fbclid=IwAR0rKBShQ_GJXR8uAwbVrhK_IhBLdLWW3ySMbot6YfEsr1y4FO5yZreLiw (acesso em: 28/10/2020)

UFSM. Podcast recupera histórias e promove integração entre docentes e alunos dos cursos de Letras. UFSM, Santa Maria, Rio Grande do Sul, 16 de Julho de 2020. Disponível em: https://www.ufsm.br/2020/06/18/podcast-recupera-historias-epromove-integracao-entre-docentes-e-alunos-dos-cursos-de-letras/ (acesso em: 28/10/2020)

VICENTE, Eduardo (2018). "Do rádio ao podcast: as novas práticas de produção e consumo de áudio". In: Emergências periféricas em práticas midiáticas [S.l: s.n.]. Disponível em: https://repositorio.usp.br/item/002906541 (acesso em: 21/10/2020)

$7 \quad$ Número do projeto no Portal de Projetos da UFSM.

8 https://www.facebook.com/PET-Letras-Laborat\%C3\%B3rio-Corpus-UFSM$2865758 \overline{14698076}$

9 https://www.instagram.com/petletraslabcorpus/ 